\title{
A EDUCAÇÃO INFANTIL NO MUNICÍPIO DE MARÍLIA (SP): A OFERTA, O ATENDIMENTO E A INFRAESTRUTURA E O PLANO NACIONAL DE EDUCAÇÃO
}

\author{
Prof. Dr. Carlos da Fonseca Brandão ${ }^{1}$ \\ Prof ${ }^{a}$ Dra. Silvana Fernandes Lopes ${ }^{2}$ \\ Prof ${ }^{a}$ Dra. Catharina Edna Rodrigues Alves ${ }^{3}$ \\ Prof ${ }^{\text {a }}$ Me. Ana Laura Jeremias Urel ${ }^{4}$
}

\section{RESUMO}

Eixo Temático 01 - Políticas Públicas e Gestão da Educação

O presente artigo apresenta os resultados de pesquisa realizada junto à Secretaria Municipal de Educação do município de Marília (SP), a qual procurou diagnosticar a situação das Escolas Municipais de Educação Infantil (EMEI's) em Marília no que se refere às questões de oferta, atendimento e infraestrutura, tendo como parâmetro principal o Plano Nacional de Educação (PNE) que vigorou até 2011 (Lei $\mathrm{n}^{\circ}$ 10.172/01). Diante da situação encontrada, o presente artigo também analisa as mesmas questões, à luz do atual Plano Nacional de Educação (PNE - Lei ${ }^{\circ}$ 13.005/14), com o objetivo de verificarmos o quão distantes estamos (ou não) da consecução da meta $n^{\circ} 1$ do atual PNE, relativa à Educação Infantil.

PALAVRAS-CHAVE: Plano Nacional de Educação. Educação Infantil. Oferta, Atendimento e Infraestrutura.

\section{THE EARLY CHILDHOOD EDUCATION IN THE CITY OF MARÍLIA (SP): THE OFFER, AND THE INFRASTRUCTURE AND THE NATIONAL EDUCATION PLAN}

\begin{abstract}
This article presents the results of a research carried out along with the Municipal Secretary of education in the city of Marília (SP), which sought to diagnose the situation of municipal Elementary Schools (EMEI) in Marilia regarding to issues of supply, service and infrastructure, having as main parameter the National Education Plan (PNE) which ran until 2011 (law $n^{\circ}$ 10.17201). Faced with the found situation, this article also analyzes the same issues, of the current National Education Plan (PNE-law $n^{\circ} 13.00514$ ), in order to check how far we are (or not) of achieving goal no. 1 of the current PNE, on early childhood education.
\end{abstract}

KEY-WORDS: National Education Plan. Early Childhood Education. Offer, service and infrastructure.

\section{Introdução}

\footnotetext{
${ }^{1}$ Professor Adjunto do Departamento de Educação da UNESP - Assis e do Programa de Pós-graduação em Educação da UNESP - Marília; email: cbrandao@assis.unesp.br

${ }^{2}$ Professora do Departamento de Educação da UNESP - São José do Rio Preto e do Programa de Pós-graduação em Educação da UNESP - Marília; email: silvanaflopes@ gmail.com

${ }^{3}$ Doutora em Educação pela UNESP - Marília e docente da graduação e da pós-graduação da Faculdade do Ensino Superior do Interior Paulista - FAIP; email: calvesro@ marlia.unesp.br

${ }^{4}$ Doutoranda do Programa de Pós-graduação em Educação da UNESP - Marília e coordenadora do curso de Pedagogia da Faculdade de Ensino Superior do Interior Paulista - FAIP; email: laura.urel@gmail.com
} 
O presente artigo apresenta os resultados de pesquisa realizada junto à Secretaria Municipal de Educação do município de Marília (SP), a qual procurou diagnosticar a situação das Escolas Municipais de Educação Infantil (EMEI's) em Marília no que se refere às questões de oferta, atendimento e infraestrutura, tendo como parâmetro principal o Plano Nacional de Educação (PNE) que vigorou até 2011 (Lei n $\left.{ }^{\circ} 10.172 / 01\right)^{5}$.

Nossa opção por focalizar as questões relativas à oferta, ao atendimento e à questão da infraestrutura física e material das escolas pesquisadas, deu-se por dois motivos: o primeiro, por acreditarmos que essas questões se constituem em um sério problema da Educação brasileira, ainda não resolvido. Posteriormente porque reforça a centralidade das questões que discutimos, os quais, são abordadas (no todo ou em parte) pelas metas de $n^{\circ} 1$ e 2 da seção destinada à Educação Infantil do antigo Plano Nacional de Educação (PNE - Lei n ${ }^{\circ}$ 10.172/01) e pela meta de $n^{\circ} 1$ do atual Plano Nacional de Educação (PNE - Lei no 13.005/14) . $^{6}$

Apesar deste artigo focar em uma única cidade do interior paulista, acreditamos que esse estudo de caso serve para como uma espécie de "fotografia" da Educação Infantil em nosso país, sem que isso signifique esquecermos das grandes diversidades existentes no país, tais como as relativas a densidade demográfica, recursos socioeconômicos, contexto cultural, condições geográficas e climáticas. Tais diversidades contextuais (e conjunturais) exigem uma abordagem de projeto pedagógico para a Educação Infantil que identifique os parâmetros fundamentais para a qualidade do ambiente das unidades de Educação Infantil e, ao mesmo tempo, ofereça condições para que as prefeituras criem uma rede de Educação infantil que se paute, prioritariamente, pela qualidade.

Este trabalho, portanto, busca ampliar os diferentes olhares sobre a Educação Infantil, a partir da análise de alguns aspectos da política educacional pública brasileira. Assim como Ball (2011, p. 39), sabemos que as pesquisas que abordam momentos muito específicos, como essa nossa pesquisa, se constituem em pesquisas cujos resultados também devem ser lidos com as devidas ressalvas. Porém, Ball também considera que os efeitos das políticas educacionais são "sentidos nos fatos sociais básicos da pobreza, da opressão e da desigualdade." (BALL, 2011, p. 47).

\footnotetext{
${ }^{5}$ Esse artigo é parte da pesquisa intitulada "Mapeamento da situação atual das escolas municipais de educação infantil (EMEI's) do centro-oeste paulista em relação às metas propostas pelo Plano Nacional de Educação (PNE 2001-2010) nas questões de oferta, atendimento e infraestrutura.", financiada pelo Conselho Nacional de Desenvolvimento Científico e Tecnológico, no âmbito do Edital nº 07/2011 MCTI/CNPq/MEC/CAPES.

${ }^{6}$ Apenas à título de esclarecimento, o antigo PNE (Lei no 10.172/01) possuía 298 metas, as quais estavam divididas por níveis e modalidades de ensino. Já o atual PNE (Lei nº 13.005/14) possui apenas 20 metas, as quais englobam os níveis e modalidades de ensino assim como alguns outros assuntos, como, por exemplo, formação de professores (BRANDÃO, 2006 e 2014).
} 
Por fim, apresentamos os dados coletados pela equipe técnica da Secretaria da Educação do município após entrevista com a Supervisora das Escolas de Educação Infantil, sobre as questões da oferta, do atendimento e da infraestrutura da Educação Infantil em Marília. Ao final desse artigo teceremos algumas considerações sobre essa temática, procurando sistematizar em que medida essas questões estão dentro dos parâmetros estabelecidos pelo antigo PNE e, talvez, também, pelo novo PNE (Lei nº 13.005/14), especificamente no município de Marília.

\section{A Educação Infantil no PNE}

O atual PNE (Lei $n^{\circ}$ 13.005/14) traz um conjunto de desafios para as políticas públicas voltadas à efetivação do direito à Educação Infantil, assim como para a interpretação dos deveres jurídicos que devem ser assumidos pelas diferentes esferas do Poder Público, principalmente pelos municípios, com a necessária (e efetiva) colaboração da União e dos estados. Assim, o atual PNE, longe de significar o esgotamento de um ciclo de regulamentação do direito à educação, abre uma nova etapa de proteção jurídica e de planejamento público para sua efetivação, na qual está prevista a edição de novas normas, além da revisão e adequação de políticas em curso, tendo como instrumento principal, no âmbito local, os planos de educação dos municípios e estados.

A atual Lei de Diretrizes e Bases da Educação Nacional (LDB - Lei no 9.394/96), conhecida no meio educacional como a "Constituição" da Educação brasileira, determina, em seus artigos 29, 30 e 31, que as instituições de Educação Infantil devem criar procedimentos para acompanhamento do trabalho pedagógico e para avaliação do desenvolvimento das crianças, sem objetivo de seleção, promoção ou classificação, garantindo a observação crítica e criativa das atividades, das brincadeiras e interações das crianças no cotidiano e tem por objetivo o desenvolvimento integral da criança, em seus aspectos físico, afetivo, psicológico, intelectual, social, complementando a ação da família e da comunidade (BRANDÃO, 2010, p. $84-85)$.

No Brasil, desde a promulgação da atual Constituição e da sanção da Lei no 8.069/90, que instituiu o Estatuto da Criança e do Adolescente (ECA), a concepção da criança como sujeito de direitos (SARMENTO, 2001, p. 24-7), que é detentora de potencialidades a serem plenamente desenvolvidas, está em sintonia com as principais normas internacionais sobre o direito da criança à Educação, quer sejam, a Declaração Universal dos Direitos da Criança 
(1959) e Convenção sobre os Direitos da Criança (1989) (TIRIBA, 2001, p. 73 e LEITE FILHO, 2001, p. 31).

Para além dos argumentos legais, sociais e econômicos, na base dessa questão está o direito ao cuidado e à Educação desde o nascimento, como elemento constitutivo da pessoa e como meio mais adequado à formação, desenvolvimento e integração social da criança. A importância da Educação pré-escolar também está presente em análises mundiais sobre a Educação. Em seu relatório final, a Comissão Internacional sobre Educação para o Século XXI - criada, oficialmente, no início de 1993, sob o patrocínio da UNESCO -, afirma que as crianças que usufruem da Educação pré-escolar "têm uma disposição mais favorável em relação à escola e correm menos riscos de a abandonar prematuramente do que as que não tiveram essa oportunidade" (DELORS, 2001, p. 129) ${ }^{7}$. Desse modo, as instituições que atendem à Educação Infantil, especialmente as pré-escolas, deverão adotar objetivos educacionais, transformandose em instituições de Educação, segundo as diretrizes curriculares nacionais específicas para a Educação Infantil (SAVIANI, 1997, p. 172) ${ }^{8}$.

Lembrando que esta é a primeira etapa da Educação Básica, sendo oferecida em creches e pré-escolas, as quais se caracterizam como espaços institucionais não domésticos, ofertada em estabelecimentos educacionais públicos ou privados, em turnos parciais ou em jornada de tempo integral, devem, por sua importância social, ser regulados e supervisionados pelos respectivos sistemas de ensino municipais e, ainda que indiretamente, ser submetida ao controle da sociedade.

No entanto, mesmo regulamentada pela atual LDB, a frequência na Educação Infantil não é pré-requisito para a matrícula no Ensino Fundamental, não podendo, de forma alguma, impedir o acesso da criança ao Ensino Fundamental (BRANDÃO, 2004, p. 57). Preferencialmente, as vagas da Educação Infantil pública devem ser oferecidas próximas às residências das crianças. Portanto, para que isso ocorra efetivamente, é essencial o levantamento detalhado da demanda por creche e pré-escola, de modo a materializar o planejamento da expansão, inclusive com os mecanismos de busca ativa de crianças em âmbito

\footnotetext{
${ }^{7}$ Não fazendo distinção entre creches e pré-escolas, mas considerando a Educação Infantil como Educação préescolar, Delors considera que a oferta dessa fase escolar traz vantagens significativas à crianças e às suas famílias, ao afirmar que uma "escolarização iniciada cedo pode contribuir para a igualdade de oportunidades, ajudando a superar as dificuldades iniciais de pobreza, ou de um meio social ou cultural desfavorecido. Pode facilitar, consideravelmente, a integração escolar de crianças vindas de famílias de imigrantes, ou de minorias culturais e linguísticas. Além disso, a existência de estruturas educativas que acolham as crianças em idade pré-escolar facilita a participação das mulheres na vida social e econômica.” (2001, p. 129).

${ }^{8}$ Para uma noção das discussões realizadas sobre Educação Infantil no Brasil e no exterior, ver, por exemplo, Faria; Palhares (1999) e Machado (2002), além dos documentos governamentais citados no decorrer desse capítulo - que ainda se encontram em discussão -, e os documentos oficiais relacionados nas referências bibliográficas.
} 
municipal, projetando o apoio do estado e da União para a expansão da rede física, quando for o caso.

$\mathrm{Na}$ questão da oferta e do atendimento da Educação Infantil no Brasil, a meta $\mathrm{n}^{\mathrm{o}} 1$ do antigo PNE (Lei ${ }^{\circ}$ 10.172/01) propunha que, até o início do ano de 2006, a oferta fosse ampliada para $30 \%$ da população de 0 a 3 anos e $60 \%$ da população de 4 e 5 anos. Também propunha que, até o início do ano de 2011 esse percentuais passassem para 50\% e 80\%, respectivamente (BRANDÃO, 2006, p. 26). Já a meta $n^{\circ} 1$ do atual PNE (Lei no 13.005/14) propõe a universalização do atendimento da Educação Infantil, no âmbito da pré-escola (crianças de 4 e 5 anos) até 2016, e, no âmbito das creches (atendimento às crianças de 0 a 3 anos) o alcance de atendimento de 50\% do total dessas crianças até o ano de 2024 (BRANDÃO, 2014, p. 15).

Na comparação direta entre as metas propostas para a questão da oferta e do atendimento da Educação Infantil brasileira, imediatamente é possível perceber que, no âmbito da préescola, a meta $\mathrm{n}^{\circ} 1$ do novo PNE avança em relação à meta $\mathrm{n}^{\circ} 1$ da Educação Infantil do antigo PNE, ao passar de $80 \%$ de atendimento para a universalização da oferta desse nível de ensino. Segundo dados do próprio Ministério da Educação (MEC), em 2013 (último dado disponível), a taxa de atendimento no nível da pré-escola (4 e 5 anos) no Brasil estava em, aproximadamente, $88 \%$, ou seja, uma meta absolutamente factível de ser alcançada até o final de 2016, como propõe a meta $\mathrm{n}^{\circ} 1$ do novo $\mathrm{PNE}^{9}$.

Por outro lado, também é possível perceber que, no âmbito da oferta e do atendimento às crianças de 0 a 3 anos, o novo PNE (Lei n ${ }^{\circ}$ 10.172/01) não avança em relação ao antigo PNE (Lei $\mathrm{n}^{\circ} 13.005 / 14$ ), visto que ambos propõem atender 50\% das crianças brasileiras dessa faixa etária, ainda que o novo PNE coloque o patamar de 50\% de atendimento nesse nível de ensino como nível mínimo a ser alcançado. $\mathrm{O}$ aspecto negativo dessa situação é constatar o fato de que, passada mais de uma década, ainda temos presente o sério problema da oferta e do atendimento da Educação Infantil no Brasil, no nível das creches, instituições essas destinadas ao atendimento das crianças de 0 a 3 anos.

Na questão da infraestrutura da Educação Infantil, a comparação entre o antigo PNE (Lei $\left.n^{o} 10.172 / 01\right)$ e o novo PNE (Lei $n^{o} 13.005 / 14$ ) é impossível de ser realizada, visto que, enquanto o PNE anterior possuía uma meta específica para essa questão (meta $\mathrm{n}^{\circ} 2$ da seção destinada à Educação Infantil), a qual continha especificações sobre a infraestrutura adequada das escolas de Educação Infantil, o atual PNE não possui nenhuma meta (ou estratégia)

\footnotetext{
${ }^{9}$ Cf. www.mec.gov.br, acesso em 24/07/2015.
} 
específica sobre esse assunto. Entendemos que esse fato não prejudica a análise aqui apresentada pois, ainda que o novo PNE não contenha metas nem estratégias para a questão da infraestrutura das escolas de Educação Infantil, é de conhecimento público que essas escolas, nos mais diferentes municípios brasileiros, possuem, em termos de infraestrutura, diferentes níveis de qualidade e adequação.

\section{A questão da oferta, do atendimento e da infraestrutura das Escolas Municipais de Educação Infantil de Marília (EMEI's)}

A Rede Municipal de Educação possui 34 escolas de Educação Infantil, sendo essas Berçários, EMEIs, EMEIs/creche e EMEFEIs e 2 entidades que atendem a crianças nessa faixaetária. O número de crianças atendidas é de 12.424 sendo contadas as matrículas de crianças de tempo integral - o que, para eles, caracteriza duplicidade no atendimento. Assim, há 9.100 matrículas nesse nível de ensino. Segundo o blog da Secretaria da Educação, Marília atende 100\% de sua demanda em Educação Infantil obrigatória: 4 e 5 anos, porém, possui uma significativa demanda não atendida dos 4 meses aos 3 anos (Creches).

Segundo informações que constam no blog da Secretaria da Educação ${ }^{10}$, foi realizada uma reunião com os diretores de escola para orientações a respeito da Lei $\mathrm{n}^{\circ} 12.796$, de 4 de Abril de $2013^{11}$ e sobre a criação de uma Central de vagas. Tal medida, segundo a Secretária, possibilitará a implementação de critérios justos e transparentes para os atendimentos de crianças de 4 meses a 3 anos no período integral (Creches), já que não há vagas para toda a demanda e, até então, o sistema para matrículas se reduzia ao critério de ordem de chegada dos pais nas escolas no dia definido para as matrículas. No ano de 2013, a Secretaria Municipal de Educação de Marília ainda não possuía o levantamento de quantas crianças, por faixas etárias, aguardavam vagas nas EMEI's e nem o levantamento de quais são as regiões da cidade em que esse problema é mais premente. Mesmo assim, estavam sendo construídas 3 creches em setores distintos do município para suprir a demanda dessas regiões e outras 5 creches estavam sendo planejadas para serem construídas até o final de 2016.

\footnotetext{
10 Outras informações podem ser encontradas no seguinte endereço: http://secretariamunicipalmarilia.blogspot.com.br/2013/10/reuniao-central-de-vagas.html.

11 Altera a Lei no 9.394, de 20 de dezembro de 1996, que estabelece as diretrizes e bases da educação nacional, para dispor sobre a formação dos profissionais da educação e dar outras providências, principalmente no que tange à obrigatoriedade de matrícula para crianças de 4 e 5 anos e a nova organização da educação infantil de 4 meses a 5 anos. Disponível em http://www.planalto.gov.br/ccivil_03/Ato2011-2014/2013/Lei/L12796.htm.
} 
A seguir temos um quadro com os dados quantitativos do número de crianças atendidas e matriculadas na Educação Infantil no município de Marília:

\begin{tabular}{|c|c|}
\hline Parcial & 9100 \\
\hline Integral & 3324 \\
\hline Emei’s/Creche & 8711 \\
\hline Berçários & 389 \\
\hline Matrículas & 9100 \\
\hline Atendimentos & 12424 \\
\hline Particulares & 685 \\
\hline Total de Matriculados & $9785-$ part/municipais \\
\hline $\begin{array}{c}\text { Total aproximado de } \\
\text { Crianças entre 0 e 5 } \\
\text { anos }\end{array}$ & 12.500 \\
\hline $\begin{array}{c}\text { Demanda total não } \\
\text { atendida }\end{array}$ & 2.715 \\
\hline
\end{tabular}

Fonte: elaboração própria a partir dos dados coletados na entrevista e no blog da Secretaria da Educação do Município de Marília

Considerando os dados obtidos, podemos afirmar que as crianças matriculadas da rede de ensino municipal, cujos dados informados são da própria Secretaria da Educação, somadas às matriculadas na rede particular de educação infantil são, aproximadamente, 9.785 crianças. De um total aproximado de 12.500 crianças que estão na faixa-etária correspondente a esse nível de ensino, quase $80 \%$ das crianças são atendidas. Se desconsiderarmos os atendimentos das instituições particulares de educação infantil, a porcentagem atendida ainda supera a meta de 50\% do PNE (2001-2010). Para o ano de 2014, a meta estipulada pela própria Secretaria Municipal de Educação de Marília era de se aumentar para 9.500 vagas na rede municipal de ensino de Marília.

No ano de 2013, a Secretaria Municipal de Educação de Marília ainda não possuía o levantamento de quantas crianças, por faixas etárias, aguardavam vagas nas EMEI's e nem o levantamento de quais são as regiões da cidade em que esse problema é mais premente. Mesmo assim, a SME de Marília estimava em quase 3.000 o total de crianças, na faixa etária da Educação Infantil, que estavam fora da escola. Para minimizar esse problema, estavam sendo construídas 3 creches em setores distintos do município e outras 5 creches estavam sendo planejadas para serem construídas até o final de 2016.

Por outro lado, o município de Marília possuía, em 2013, 9.100 crianças matriculadas em instituições de Educação Infantil com jornada parcial, sendo 8.711 crianças em EMEI's (jornada parcial) e 389 crianças em berçários. Marília também possuía, em 2013, 3.324 crianças matriculadas em EMEI's cuja jornada escolar é de tempo integral. Esse conjunto de matrículas produz, aproximadamente, um total de quase 12.500 atendimentos/ano. 
De acordo com a equipe técnica, das 34 escolas de educação infantil, apenas 4 escolas ainda não estão adequadas quanto à infraestrutura: espaços, materiais e mobiliários, porém, essas estão no processo de reforma, porém, o espaço ainda é uma fragilidade nessas instituições de Marília. O pacote de reformas abrange, por exemplo, instalação de postes de iluminação na área próxima da e na quadra, construção de sanitários e depósito anexo à quadra, colocação de portas de correr no refeitório, cobertura nos portões de entrada e saída dos alunos, entre pátio coberto e quadra, construção de tanque de areia coberto, construção de quiosque, instalação de playground e campo de futebol com traves, entre outras modificações na estrutura das escolas. Quanto às adequações para alunos com necessidades especiais, a equipe técnica afirma que em todas as escolas já foram realizadas mudanças nesse sentido.

\section{Considerações finais}

A pesquisa presente foi realizada, primeiramente, a partir de contato direto com os responsáveis pela Secretaria Municipal de Educação de Marília. Buscamos informações junto aos responsáveis pela área de Educação Infantil do município de Marília e a respectiva equipe técnica. Como, naquele momento, ainda não havia sido iniciado o Censo Escolar, os dados obtidos foram os dados disponíveis pela Secretaria Municipal de Educação de Marília, tendo como referência o início do ano de 2013.

Assim que tivemos acesso aos dados, percebemos que precisaríamos pesquisar em outras fontes algumas informações. Dessa maneira, encontramos alguns dados no blog da Secretaria da Educação, nos sites do Instituto Brasileiro de Geografia e Estatística (IBGE), do Instituto Nacional de Estudos e Pesquisas Educacionais (INEP) e do Programa das Nações Unidas para o Desenvolvimento (Pnud), os quais apresentam informações diferentes quanto ao número de matrículas e número de crianças na faixa etária correspondente à educação infantil.

Em relação à oferta de vagas e demanda, podemos afirmar que as crianças, entre 4 meses e 5 anos, matriculadas nas escolas de educação infantil da rede municipal de ensino são, aproximadamente, 9.100. De um total aproximado de 12.500 crianças (dado encontrado no site do IBGE) nessa faixa de idade, podemos concluir que quase $75 \%$ das crianças são atendidas, nas duas etapas da educação infantil. Com a expansão das vagas programada para o ano de 2014, a Secretaria espera atender mais 400 crianças.

Por um lado, a própria Secretaria Municipal de Educação de Marília admite que ainda não há vagas suficientes para atender às crianças de 4 meses a 3 anos (vagas nas creches), por 
outro lado, a mesma afirma que atende toda a demanda entre 4 e 5 anos, cujo atendimento passará a ser obrigatório a partir de 2017. Com os dados obtidos, podemos afirmar que o município de Marília atende, no que tange à pré-escola, as metas estabelecidas pelo antigo e pelo novo Plano Nacional de Educação pois à meta $n^{\circ} 1$ da Educação Infantil do antigo PNE era alcançar $80 \%$ de atendimento e o novo PNE propõe a universalização da oferta desse nível de ensino, já atingida pelo município de Marília.

Quanto à infraestrutura, foi relatado que as escolas de educação infantil, de uma maneira geral, apresentam boas condições de atendimento, com bons espaços, materiais e mobiliários. Entre as escolas, apenas 4 escolas (EMEI's) não estão conforme o padrão ideal, mas estão no plano de reformas para este e próximo anos. Como o atual Plano Nacional de Educação não possui metas nem estratégias específicas com relação à infraestrutura das EMEI's, estamos considerando como padrão ideal o proposto pela meta $\mathrm{n}^{\circ} 2$ da Educação Infantil do antigo Plano Nacional de Educação (Lei n $\left.{ }^{\circ} 10.172 / 01\right)$ e, portanto, podemos afirmar que, também nessa questão, as EMEI's existentes no município de Marília possuem boas condições de infraestrutura.

No geral, consideramos que as três metas analisadas (quanto à oferta, demanda e infraestrutura), estão sendo alcançadas pela rede municipal de educação infantil do município de Marília. Cabe destacar que também localizamos, no âmbito da rede municipal de educação do município de Marília, ações referentes à formação continuada docente, à qualidade da merenda escolar, ao sistema de matrículas, que, entre outras, se constituem em ações empreendidas com o objetivo da melhoria da qualidade da Educação Infantil ofertada por este município, ainda que, por outro lado, tenha sido possível constatar algumas falhas, entre as quais destacamos a ausência de um plano de carreira para o magistério municipal e falta de docentes em número suficiente.

\section{REFERÊNCIAS}

ÀRIES, P. História social da família e da criança. Rio de Janeiro: Guanabara Koogan, 1981. BALL, S. J. Sociologia das políticas educacionais e pesquisa crítico-social: uma revisão pessoal das políticas educacionais e da pesquisa em política educacional. In: BALL, S. J.; MAINARDES, J. (Orgs.). Políticas educacionais: questões e dilemas. São Paulo: Cortez, 2011.

BRANDÃO, C. F. Os desafios do novo Plano Nacional de Educação (PNE - Lei no 13.005/14): comentários sobre suas metas e suas estratégias. São Paulo: Avercamp, 2014.

LDB passo a passo: lei de diretrizes e bases da educação nacional - Lei $n^{\circ}$ 9.394/96, comentada e interpretada, artigo por artigo. 4. ed., São Paulo: Avercamp, 2010. 
PNE passo a passo: discussão dos objetivos e metas do Plano Nacional de Educação (PNE - Lei no 10.172/01). São Paulo: Avercamp, 2006.

Estrutura e funcionamento do ensino. São Paulo: Avercamp, 2004.

BRASIL. Lei no 12.796, de 4 de Abril de 2013. Altera a Lei no 9.394, de 20 de dezembro de 1996, que estabelece as diretrizes e bases da educação nacional, para dispor sobre a formação dos profissionais da educação e dar outras providências. Disponível em http://www.planalto.gov.br/ccivil_03/_Ato2011-2014/2013/Lei/L12796.htm. Acesso em 20 nov de 2013. nov. 2013.

Censo Escolar. Disponível em: <http://portal.inep.gov.br/basica-censo $>$. Acesso em 04

IBGE Cidades. Disponível em: $\langle$ http://cidades.ibge.gov.br/xtras/perfil.php?lang=\&codmun=350400>. Acesso em 04 nov. 2013.

DELORS, J. Educação: um tesouro a descobrir (Relatório para a UNESCO da Comissão Internacional sobre Educação para o século XXI). 6. Ed. São Paulo: Cortez; Brasília, DF: MEC: UNESCO, 2001.

FARIA, A. L. G.; PALHARES, M. S. (Orgs.). Educação infantil pós-LDB: rumos e desafios. Campinas/São Carlos/Florianópolis: Autores Associados/Ed. UFSCar/Ed. UFSC, 1999 (Coleção Polêmicas do nosso tempo; 62).

LEITE FILHO, A. Proposições para uma educação infantil cidadã. In: GARCIA, R. L.; LEITE FILHO, A. (Orgs.). Em defesa da educação infantil. Rio de Janeiro: DP\&A, 2001, p. 29-58, (Coleção O sentido da escola; 18).

MACHADO, M. L. A. (Org.). Encontros e desencontros em educação infantil. São Paulo: Cortez, 2002.

MARILIA. Blog da Secretaria da Educação de Marília. Disponível em: http://secretariamunicipalmarilia.blogspot.com.br/. Acesso em 04 nov. 2013

Secretaria Municipal de Educação de Marília. Disponível em: http://www.marilia.sp.gov.br/prefeitura/?page_id=361. Acesso em 04 nov. 2013.

SARMENTO, M. J. A globalização e a infância: impactos na condição social e na escolaridade. In: GARCIA, R. L.; LEITE FILHO, A. (Orgs.). Em defesa da educação infantil. Rio de Janeiro: DP\&A, 2001, p. 13-28 (Coleção O sentido da escola; 18).

SAVIANI, D. A nova lei da educação: trajetória, limites e perspectivas. Campinas: Autores Associados, 1997 (Coleção Educação contemporânea).

TIRIBA, L. Pensando mais uma vez e reinventando as relações entre creche e famílias. In: GARCIA, R. L.; LEITE FILHO, A. (Orgs.). Em defesa da educação infantil. Rio de Janeiro: DP\&A, 2001, p. 59-80 (Coleção O sentido da escola; 18). 